\title{
Determination of an Optimum Fictitious Air Gap and Rotor Disk Thickness for a Coreless AFPMM
}

\author{
Franjo PRANJIĆ, Peter VIRTIČ
}

\begin{abstract}
This article presents the research on the optimum distance (fictitious air gap) between permanent magnets of the coreless axial flux permanent magnet machine with a double rotor and single stator. Magnetic flux density of the permanent magnets follows the mean flux path between the opposite magnets. The size of the leakage flux depends on the axial distance between the magnets, the distance between adjacent magnets and the back iron of the rotor disks. If the fictitious air gap (clearance between opposite permanent magnets) is too large, the flux path will close through the adjacent magnet and not the opposite one. The article presents the finite element analysis of the magnetic flux density between the permanent magnets mounted on the rotor disks where the fictitious air gap thickness was set as a variable to determine the maximum clearance. Connection between bending (pull) forces of rotor disks and fictitious air gap thickness is also presented with the mechanical stress analysis of rotor disks.
\end{abstract}

Keywords: Axial Flux Permanent Magnet Machine (AFPMM); Mechanical Stress Analysis (MSA); optimum fictitious air gap thickness; rotor disk thickness

\section{INTRODUCTION}

Axial flux permanent magnet machines (AFPMM) are growing more and more popular lately due to their compactness, a high degree of reliability, efficiency, simple construction and high power density [1-7]. As shown in Fig.1, this type of machines, which are also called "disk" type machines, have various topologies:

- $\quad$ single-sided (one stator and one rotor)

- double-sided (single stator - double rotor or single rotor - double stator)

- multistage (multiple rotors and stators).
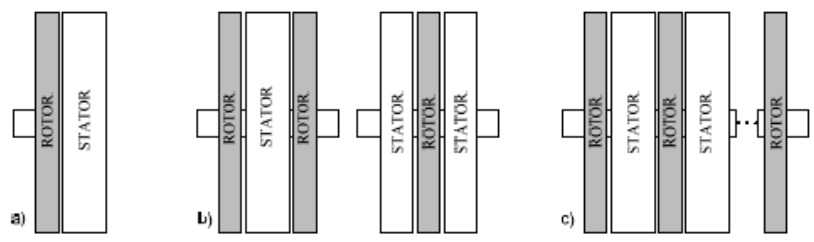

Figure 1 Basic topologies of AFPMM: a) single-sided, b) double-sided, c) multistage

All of the above-mentioned topologies can be constructed with or without iron cores (coreless) and with surface mounted or buried PMs. Low power PM machines are usually coreless and have surface mounted PMs [1].

Each machine topology has its own strengths and weaknesses. Topologies without stator cores are used for low and medium power generators and have the advantages, such as absence of cogging torque, linear torque-current characteristics, high power density and compact construction.

Due to the absence of the stator core losses, this type of generators can operate with a higher efficiency than the conventional generators [2-5].

This article presents the determination of the optimum size of the fictitious air gap thickness for AFPMM with two external rotors and one internal coreless stator (without ferromagnetic material as the copper windings are held together in position by using a composite material of epoxy resin), using numerous finite element analysis (FEA) simulations in Ansys Maxwell 3D software.

As the name itself states, the axial flux machine requires magnetic flux to pass in the axial direction. If the thickness of fictitious air gap is too large (usually this means large stator thickness), the magnetic flux path will close through the air and into the same PM or through the adjacent PM. Consequently, a very small portion of magnetic flux will pass in axial direction (large leakage flux), and the machine will produce smaller torque and electromotive force (EMF).

Finding an optimum thickness of fictitious air gap allows the highest possible portion of magnetic flux to pass from PM on one rotor disk to the PM on opposite rotor disk with minimal flux leakage.

Since the magnetic flux density in the fictitious air gap is one of the key values for calculation of static torque, back EMF and pull forces between opposite rotor disks, the derivation of equation for magnetic flux density in the fictitious air gap is presented with a magnetic equivalent circuit (MEC).

The relation between magnetic flux density and back EMF is presented with Eq. (1) and Eq. (2) [3]:

$$
\begin{aligned}
& e=-N \frac{\mathrm{d} \Phi}{\mathrm{d} t} \\
& \Phi=\iint_{S} B \mathrm{~d} S
\end{aligned}
$$

where $B$ is the magnetic flux density, $N$ the number of turns in a coil, $e$ the EMF, $\mathrm{d} \Phi / \mathrm{d} t$ the time variation of magnetic flux within the coil, $\mathrm{d} S$ the integration surface, and $\Phi$ the magnetic flux.

The mechanical stress analysis (MSA) of rotor disks is presented since magnetic pull forces and the thickness of rotor disks depend on the air gap flux density.

The MSA has been introduced in several publications. In [8], the authors present the MSA for a high speed AFPMM, where they analyze the stress level of the rotor disks due to high-speed rotation, using three-dimensional finite element method (3D FEM). Fei et al. present simplified 2D and 3D FEM for analysis and design of rotor disks of high-speed AFPM generators in [9]. Rani et al. present a computational method of rotor stress analysis for conventional rotors using J-MAG software in [10]. In [11], the authors present the structural analysis of low-speed axial-flux permanent-magnet machines. Timoshenko 
derived the equations for bending circular plates in [12], and in [13], Young and Budynas present various scenarios for different loads on circular plates.

The link between electromagnetic and structural designs is Maxwell stress. To determine the air gap flux density, classical analysis of magnetic equivalent circuits can be used, hence the Maxwell stress is given by:

$$
q=\frac{B_{\mathrm{d}}^{2}}{2 \mu_{0}}
$$

where $q(\mathrm{~Pa})$ is the Maxwell stress, $B_{\mathrm{d}}$ the axial component of air gap flux density and $\mu_{0}$ the permeability of vacuum [10].

Maxwell stress is represented by the magnetic pull force acting between the rotor disks and can be calculated as magnetic pressure multiplied by active surface area of all PMs (SPM) as shown in [1]:

$$
\begin{aligned}
& F=\frac{B_{\mathrm{d}}^{2}}{2 \mu_{0}}\left(S_{\mathrm{PM}}\right) \\
& S_{\mathrm{PM}}=\alpha_{i} \frac{\pi}{4}\left(D_{\text {out }}^{2}-D_{\text {in }}^{2}\right) \\
& \alpha_{i}=\frac{\alpha_{\mathrm{PM}} 2 p}{360}
\end{aligned}
$$

where $F$ is the pull force between opposite PMs, $\alpha_{\mathrm{PM}}$ the angle of PMs, $\alpha_{\mathrm{i}}$ the coefficient, which is calculated as angle of PMs multiplied by the number of PMs per rotor disk (poles) and divided by 360 degrees, and $D_{\text {out }}$ and $D_{\text {in }}$ are the outer and inner diameters of PMs, respectively.

In [13], the authors present equations for various types of loads on a circular plate where the case suitable for rotor disks of AFPMM with surface mounted PMs is presented in Fig. 2.

Equations for deflection calculations are [12-14]:

$$
\begin{aligned}
& y_{\mathrm{a}}=M_{\mathrm{rb}} \frac{a_{\mathrm{r}}^{2}}{D} C_{2}+Q_{\mathrm{b}} \frac{a_{\mathrm{r}}^{3}}{D} C_{3}+q \frac{a_{\mathrm{r}}^{4}}{D} L_{11} \\
& M_{\mathrm{rb}}=\frac{-q a_{\mathrm{r}}^{2}}{C_{8}}\left(\frac{C_{9}}{2 a_{\mathrm{r}} b_{\mathrm{r}}}\left(a_{\mathrm{r}}^{2}-r_{0}^{2}\right)-L_{17}\right) \\
& Q_{\mathrm{b}}=\frac{q}{2 b_{\mathrm{r}}}\left(a_{\mathrm{r}}^{2}-r_{0}^{2}\right) \\
& C_{2}=\frac{1}{4}\left(1-\left(\frac{b_{\mathrm{r}}}{a_{\mathrm{r}}}\right)^{2}\left(1+2 \ln \left(\frac{a_{\mathrm{r}}}{b_{\mathrm{r}}}\right)\right)\right) \\
& C_{3}=\frac{b_{\mathrm{r}}}{4 a_{\mathrm{r}}}\left(\left(\left(\frac{b_{\mathrm{r}}}{a_{\mathrm{r}}}\right)^{2}+1\right) \ln \left(\frac{a_{\mathrm{r}}}{b_{\mathrm{r}}}\right)+\left(\frac{b_{\mathrm{r}}}{a_{\mathrm{r}}}\right)^{2}-1\right) \\
& C_{8}=\frac{1}{2}\left(1+v+(1-v)\left(\frac{b_{\mathrm{r}}}{a_{\mathrm{r}}}\right)^{2}\right) \\
& C_{9}=\frac{b_{\mathrm{r}}}{a_{\mathrm{r}}}\left(\frac{1+v}{2} \ln \left(\frac{a_{\mathrm{r}}}{b_{\mathrm{r}}}\right)+\frac{1-v}{4}\left(1-\left(\frac{b_{\mathrm{r}}}{a_{\mathrm{r}}}\right)^{2}\right)\right)
\end{aligned}
$$

$$
\begin{aligned}
& D=\frac{E t^{3}}{12\left(1-v^{2}\right)} \\
& L_{17}=\frac{1}{4}\left(1-\frac{1-v}{4}\left(1-\left(\frac{r_{0}}{a_{\mathrm{r}}}\right)^{4}\right)-\right. \\
& \left.-\left(\frac{r_{0}}{a_{\mathrm{r}}}\right)^{2}\left(1+(1+v) \ln \left(\frac{a_{\mathrm{r}}}{r_{0}}\right)\right)\right) \\
& L_{11}=\frac{1}{64}\left(1+4\left(\frac{r_{0}}{a_{\mathrm{r}}}\right)^{2}-5\left(\frac{r_{0}}{a_{\mathrm{r}}}\right)^{4}-\right. \\
& \left.-4\left(\frac{r_{0}}{a_{\mathrm{r}}}\right)^{2}\left(2+\left(\frac{r_{0}}{a_{\mathrm{r}}}\right)^{2}\right) \ln \left(\frac{a_{\mathrm{r}}}{r_{0}}\right)\right)
\end{aligned}
$$

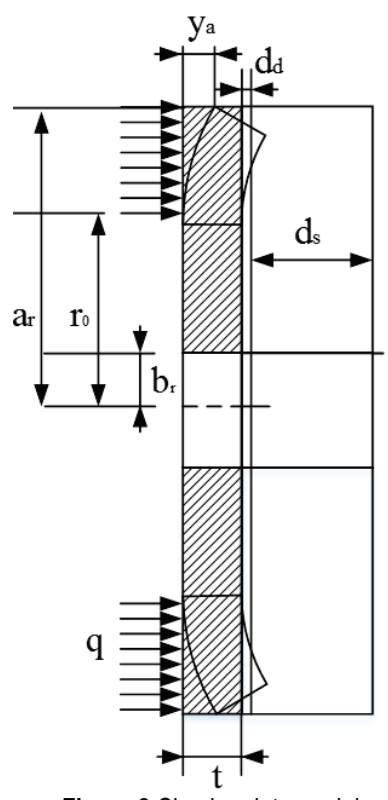

Figure 2 Circular plate model

where: $y_{\mathrm{a}}$ is the deflection of the rotor disk, $M_{\mathrm{rb}}$ the bending moment, $a_{\mathrm{r}}$ the outer radius of the rotor disk, $b_{\mathrm{r}}$ the inner radius of the rotor disk, $r_{0}$ the radial location of unit line loading or start of a distributed load, $D$ the stiffness factor of the material, $Q_{\mathrm{b}}$ the unit shear force (force per unit of circumferential length), and $q$ the magnetic pressure (or Maxwell stress). $C_{2}, C_{3}$ and $C_{9}$ are the plate constants dependent upon the ratio $a / b$, and $L_{11}$ and $L_{17}$ are the loading constants dependent upon the ratio $a / r_{0} . v$ is the Poisson's ratio, $D$ a constant termed the "flexural stiffness" or "flexural rigidity", $E$ the elastic module of the material used, $t$ the thickness of the rotor disk.

Eq. (3) - Eq. (16) are used to determine the optimum rotor disk thickness through deflection of rotor disks, based on the axial component of magnetic flux density.

Finally, the conclusions of the research are presented, such as the direct link between the thickness of fictitious air gap, deflection of rotor disks and rotor disk thickness through magnetic flux density in the fictitious air gap.

In this article, a direct link between magnetic flux density and optimum thickness of fictitious air gap is presented for the first time as well as a modified equation for deflection of rotor disks together with a simple 
methodology for determining the optimum thickness of the fictitious air gap.

\section{METHODS}

\subsection{Analytical Determination of Magnetic Flux Density in the Fictitious Air Gap}

The AFPMM considered in this article is a doublesided AFPMM with two external rotors and one internal coreless stator. It was analysed in [3] and optimized in [14] by using evolutionary optimization with a genetic algorithm and an analytical evaluation of objective functions. Also in [15] the rotor disk thickness was analysed in relation to the magnitudes of magnetic flux density.

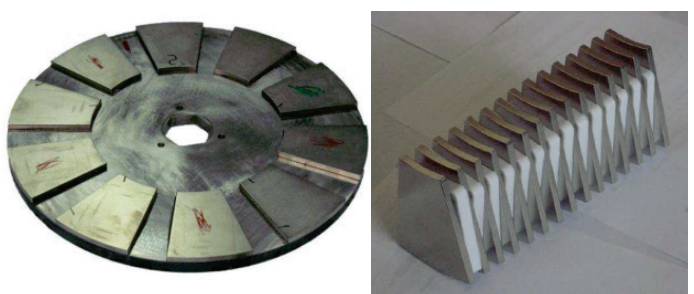

Figure 3 Rotor and Permanent magnets of a coreless AFPMM
Tab. 1 shows the data relevant to this study, and Fig. 3 shows the rotor disks with surface mounted PMs.

Table 1 geometry and parameters of analysed AFPMM)

\begin{tabular}{|c|l|c|}
\hline Symbol & \multicolumn{1}{|c|}{ Quantity } & Value/Unit \\
\hline$R$ & Rotor disk radius & $150 \mathrm{~mm}$ \\
\hline$t$ & Rotor disk thickness & $7 \mathrm{~mm}$ \\
\hline PM & Type of PM & NdFeB \\
\hline$h_{\mathrm{PM}}$ & Permanent magnet thickness & $5 \mathrm{~mm}$ \\
\hline$\tau_{\mathrm{PM}}$ & Magnetic pitch & $25^{\circ}$ \\
\hline$R_{\mathrm{inPM}}$ & Inner radius of PM & $80 \mathrm{~mm}$ \\
\hline$R_{\mathrm{outPM}}$ & Outer radius of PM & $150 \mathrm{~mm}$ \\
\hline$B_{\mathrm{r}}$ & Remanent magnetic flux density & $1,22 \mathrm{~T}$ \\
\hline$\tau_{\mathrm{p}}$ & Pole pitch & $36^{\circ}$ \\
\hline$p$ & Number of pole pairs & 5 \\
\hline$\mu_{\mathrm{r}}$ & Relative recoil permeability & 1,0704 \\
\hline$I$ & Rated current & $10 \mathrm{~A}$ \\
\hline$k_{\mathrm{W}}$ & Winding factor & 0,966 \\
\hline
\end{tabular}

In Fig. 4 the fictitious air gap is the mechanical clearance between the opposite permanent magnets, where $d$ is the fictitious air gap, $d_{\mathrm{s}}$ the stator thickness, $d_{\mathrm{d}}$ the air gap thickness, and $l_{\mathrm{AM}}$ the distance between adjacent magnets.

Path 1 represents the mean magnetic flux. The magnetic flux that does not follow the mean flux path (path 1 ) is considered to be leakage flux and represented by path 2 (magnet to air) and path 3 (magnet to magnet).

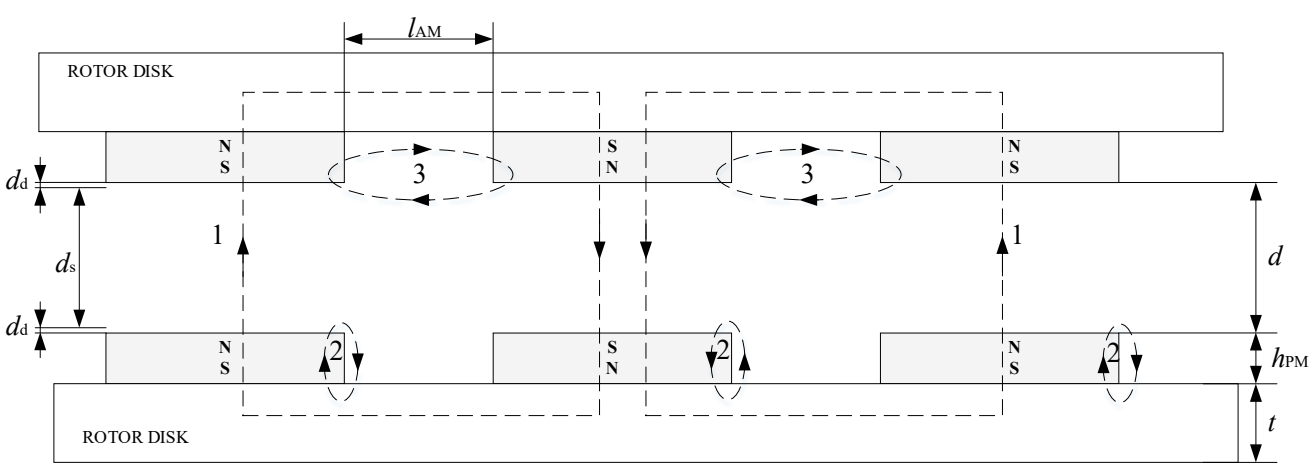

Figure 4 Sectional view of AFPMM

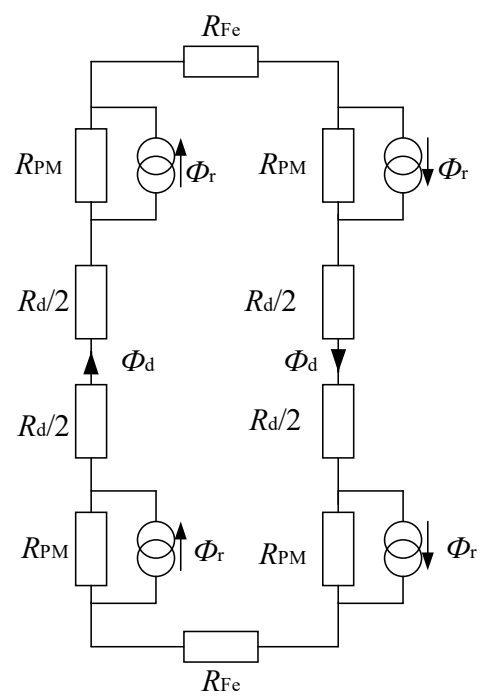

Figure 4 Magnetic equivalent circle of coreless AFPMM

Fig. 5 shows the equivalent magnetic circuit of the coreless AFPMM, where $R_{\mathrm{Fe}}$ is the reluctance of the iron disks, $R_{\mathrm{PM}}$ is the reluctance of the permanent magnets, $R_{\mathrm{d}}$ is the reluctance of the fictitious air gap, and $\Phi_{\mathrm{r}}$ and $\Phi_{\mathrm{d}}$ are the magnetic flux through the PMs and through the fictitious air gap respectively.

In an ideal situation, the magnetic flux would follow the mean flux path, but in reality, there is also the leakage flux, which can be reduced (for coreless AFPMM) by using measures listed in [16]:

- the axial length of the air gap has to be smaller than double thicknesses of the PMs in the magnetization direction $\left(d<2 h_{\mathrm{PM}}\right)$,

- the distance between neighboring PMs on the same disk has to be larger than the fictitious air gap $\left(l_{\mathrm{AM}}>d\right)$.

These measures work under the assumption that the magnetic flux will always follow the shortest path from one pole to another.

Since this type of AFPMM has no ferromagnetic stator core, a simplified MEC (magnetic equivalent circuit) is defined by neglecting iron rotor yoke reluctance due to the high permeability of steel, where magnets are represented by a flux source with parallel reluctance defined by their nominal magnetization values and geometry. 

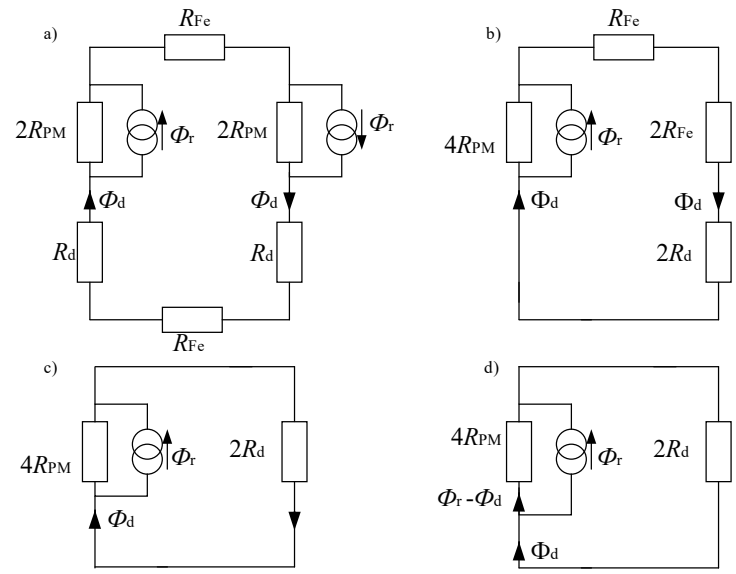

Figure 5 Simplifications of the magnetic network model of coreless AFPMM

Using the second Kirchhoff law in Fig. 6d, the equation for magnetic flux density in the middle of the air gap (axial component) can be determined. The saturation of rotor back iron is also neglected since the relative permeability of steel is considered infinite compared to the permeability of air [8].

Using the relation from Fig. 6d under assumption that the area of PMs and air gap are equal, the equation for calculating the magnetic flux density can be written as:

$$
\begin{aligned}
& B_{\mathrm{d}} A_{\mathrm{d}}=\frac{\frac{h_{\mathrm{PM}}}{\mu_{0} \mu_{\mathrm{r}} A_{\mathrm{PM}}} B_{\mathrm{r}} A_{\mathrm{PM}}}{\frac{h_{P M}}{\mu_{0} \mu_{\mathrm{r}} A_{\mathrm{PM}}}+0,5 \frac{d}{\mu_{0} A_{\mathrm{d}}}} \\
& B_{\mathrm{d}}=\frac{\frac{h_{\mathrm{PM}}}{\mu_{0} \mu_{\mathrm{r}}} B_{\mathrm{r}}}{\frac{h_{\mathrm{PM}}}{\mu_{0} \mu_{\mathrm{r}}}+0,5 \frac{d}{\mu_{0}}}=\frac{h_{\mathrm{PM}} B_{\mathrm{r}}}{h_{\mathrm{PM}}+0,5 d \mu_{\mathrm{r}}} \\
& B_{\mathrm{d}}=\frac{B_{\mathrm{r}}}{1+\frac{0,5 d \mu_{\mathrm{r}}}{h_{\mathrm{PM}}}}
\end{aligned}
$$

Mean flux path from one pole to the other is through the fictitious air gap $(d)$, which represents the stator thickness $\left(d_{\mathrm{s}}\right)$ and the thickness of the two air gaps $\left(2 d_{\mathrm{d}}\right)$. The equation for magnetic flux density in the air gap takes its final form:

$$
B_{\mathrm{d}}=\frac{B_{\mathrm{r}}}{1+\frac{0,5\left(d_{\mathrm{s}}+2 d_{\mathrm{d}}\right) \mu_{\mathrm{r}}}{h_{\mathrm{PM}}}}
$$

where $B_{\mathrm{r}}$ is permanent magnetic flux density in the air gap, $h_{\mathrm{PM}}$ the permanent magnet thickness and $\mu_{\mathrm{r}}$ the relative recoil permeability of the PMs.

Fig. 4 - Fig. 6 and Eq. (18) show that the fictitious air gap has a significant influence on the magnetic flux density. Thicker air gap means smaller magnetic flux density in axial direction.

\subsection{Determination of Optimum Fictitious Air Gap Thickness}

AFPMM model is constructed using Ansys Maxwell 3D software and the data from Tab. 1. Fig. 7a shows the starting model of the study, which consists of two $7 \mathrm{~mm}$ thick rotor disks with 10 PMs mounted on each one. Between them, there is a $100 \mathrm{~mm}$ air gap with $5 \mathrm{~mm}$ layers. Each air gap layer represents a new FEA simulation of air gap flux density (i.e., Fig. 7b shows the meshed model with $55 \mathrm{~mm}$ fictitious air gap), which is analyzed on a line that runs through both rotor disks, all the air gaps and 2 PMs. The line is drawn through the centre of the PMs on the average radius, as shown in Fig. 8.

FEA simulations are performed for the thickness of fictitious air gap from $5 \mathrm{~mm}$ to $100 \mathrm{~mm}$ with $5 \mathrm{~mm}$ steps, which in total represents 20 simulations. The result of each simulation is the axial component of the magnetic flux density on the centerline (Fig. 8) between opposite PMs.

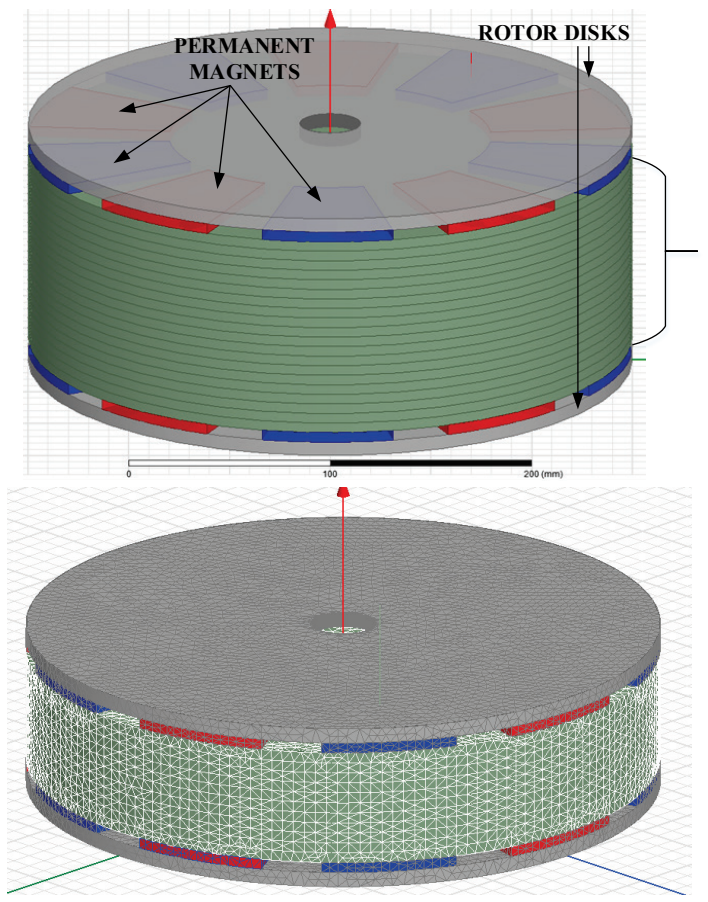

Figure 7 AFPMM model ( a-starting model with $100 \mathrm{~mm}$ fictitious air gap b-meshed model with $55 \mathrm{~mm}$ fictitious air gap)

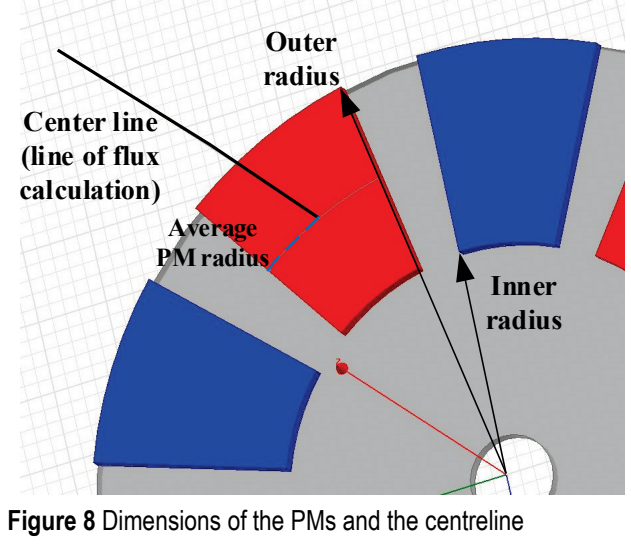

2.3 Mechanical Stress Analysis of Rotor Disks

Deflection of rotor disks is calculated with Eq. (3) and Eq. (6) - Eq. (16) together with the magnetic flux densities 
in the middle of the fictitious air gap from Tab. 2. Based on the results, the optimum disk thickness can be determined in order to reduce the weight of the machine, since rotor disks represent around $40 \%$ of total weight of the machine [1].

Deflection of rotor disks is caused by the magnetic pressure which results from the PMs. For that reason, the equation for calculating deflection of rotor disks (Eq. (7)) is modified with Eq. (6), since the authors in [12] and [13] derived the equations for bending circular plates with uniformly distributed loads. A new equation for deflection of rotor disks takes the form of Eq. (19):

$y=\alpha_{\mathrm{i}} y_{\mathrm{a}}$

where $\alpha_{\mathrm{i}}$ is the angle of PMs multiplied by the number of PMs per rotor disk (poles) and divided by 360 degrees, and ya is the deflection derived in [12].

The MSA is performed for the $7 \mathrm{~mm}$ thickness of rotor disk using analytically calculated (using Eq. (18)) and FEA gained axial component of magnetic flux density in the middle of the fictitious air gap.

Pull force between opposite rotor disks is calculated using Eq. (4) and Eq. (5) for analytically calculated and FEA gained magnetic flux density in the middle of the fictitious air gap. In addition, the deflection of rotor disks is determined analytically with Eq. (19) and with FEA, using Solid works software. In total, four deflections of rotor disks are calculated and presented.

\section{RESULTS AND DISCUSSION}

\subsection{Determination of Optimum Fictitious Air Gap Thickness}

Fig. 9 presents the results of FEA simulations for the thicknesses of the fictitious air gap from $5 \mathrm{~mm}$ to $100 \mathrm{~mm}$ with $5 \mathrm{~mm}$ steps. It shows that sectional magnets with 5 $\mathrm{mm}$ thickness have the optimum fictitious air gap up to 20 $\mathrm{mm}$ thickness since there is negligible difference in the axial component of magnetic flux density in the middle of the fictitious air gap and near the PMs. For larger air gaps, these values start to differentiate, the larger the air gap, the larger the difference.

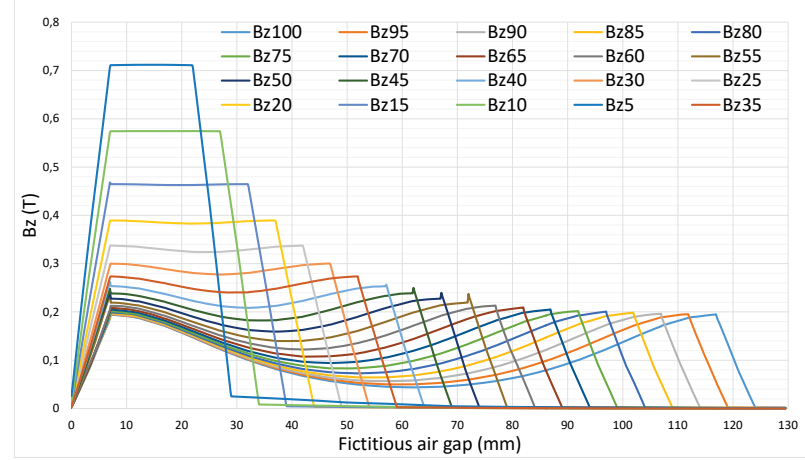

Figure 9 Magnetic flux density in axial direction for all air gaps

The values of axial component of magnetic flux density near the PMs and in the middle of the fictitious air gaps are respectively marked as $B_{z_{-} \max }$ and $B_{z_{-} \min }$ in Fig. 10, which shows a single value waveform for $5 \overline{5 m}$ air gap thickness.

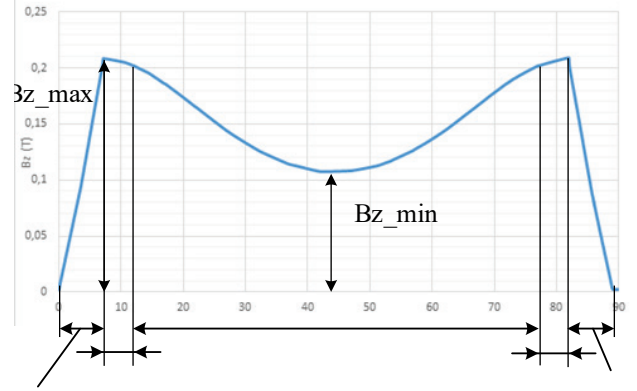

Figure 10 Positions of maximum and minimum axial component magnetic flux density

Tab. 2 and Fig. 11 show maximum and minimum values of magnetic flux density in axial direction between the PMs.

Table 2 Axial component of magnetic flux density in the fictitious air gap (FEA)

\begin{tabular}{|c|c|c|c|}
\hline $\begin{array}{c}\text { Fictitious air } \\
\text { gap thickness } d \\
(\mathrm{~mm})\end{array}$ & $B_{z_{-} \min }(\mathrm{T})$ & $B_{z_{-} \max }(\mathrm{T})$ & $\begin{array}{c}\text { Difference } \\
(\%)\end{array}$ \\
\hline 1 & 0,8448 & 0,8448 & 0 \\
\hline 5 & 0,711825 & 0,711825 & 0 \\
\hline 10 & 0,574517 & 0,574517 & 0 \\
\hline 15 & 0,462765 & 0,468164 & 1,15323 \\
\hline 20 & 0,382824 & 0,389489 & 1,71122 \\
\hline 25 & 0,324058 & 0,337344 & 3,93841 \\
\hline 30 & 0,277382 & 0,300347 & 7,64616 \\
\hline 35 & 0,24023 & 0,273567 & 12,1860 \\
\hline 40 & 0,208391 & 0,262567 & 20,6332 \\
\hline 45 & 0,182382 & 0,249802 & 26,9894 \\
\hline 50 & 0,159055 & 0,242391 & 34,3808 \\
\hline 55 & 0,139678 & 0,236783 & 41,0101 \\
\hline 60 & 0,122135 & 0,213067 & 42,6777 \\
\hline 65 & 0,107387 & 0,209165 & 48,6592 \\
\hline 70 & 0,094125 & 0,205 & 54,0854 \\
\hline 75 & 0,083002 & 0,201669 & 58,8425 \\
\hline 80 & 0,072718 & 0,200631 & 63,7554 \\
\hline 85 & 0,06430451 & 0,198421343 & 67,5919 \\
\hline 90 & 0,056541924 & 0,196034607 & 71,1572 \\
\hline 95 & 0,049904851 & 0,195151265 & 74,4276 \\
\hline 100 & 0,043782218 & 0,194908347 & 77,5370 \\
\hline & & & \\
\hline
\end{tabular}

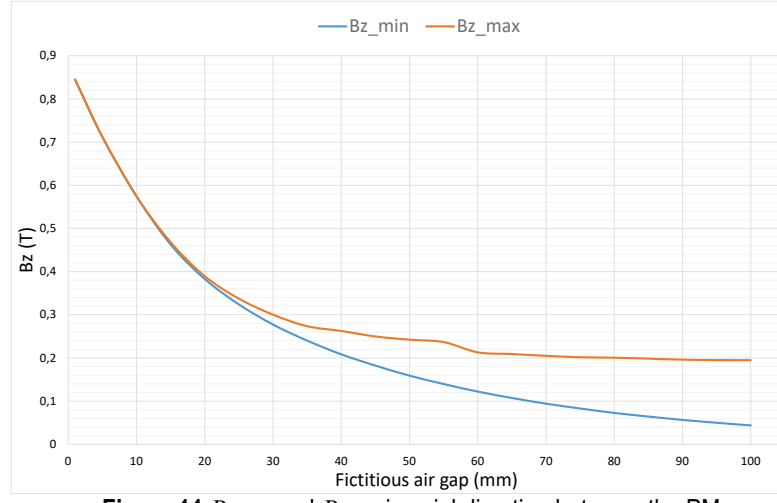

Figure $11 B_{z_{-} \text {max }}$ and $B_{z_{-} \min }$ in axial direction between the PMs

The optimum thickness of fictitious air gap is selected in such a way that there is minimum flux leakage, which means that the magnetic flux is following the mean flux path in full.

Tab. 2 shows that the values of axial component of magnetic flux density do not change for $10 \mathrm{~mm}$ thickness of fictitious air gap, which means that there is no leakage flux. Negligible change of axial component of magnetic flux density can be seen for 20 or even $25 \mathrm{~mm}$ thickness. 
The data are graphically shown in Fig. 11, and it is clear that the magnetic flux density changes exponentially in relation to the thickness of fictitious air gap.

Results in Tab. 2 also confirm the measure for reducing the flux leakage (axial length of the air gap has to be smaller than double thicknesses of the PMs in the magnetization direction).

\subsection{Mechanical Stress Analysis of Rotor Disks}

Pull forces between opposite rotor disks are calculated using Eq. (4) and Eq. (5) for analytically and FEA gained axial component of magnetic flux density and are presented in Tab. 3 and Fig. 12.

Table 3 Pull forces on rotor disks due to analytically and with FEA gained $B_{\mathrm{z}}$

\begin{tabular}{|c|c|c|c|c|}
\hline $\begin{array}{c}\text { Fictitious air } \\
\text { gap thickness } d \\
(\mathrm{~mm})\end{array}$ & $\begin{array}{c}B_{\mathrm{Z}}(\mathrm{T}) \\
\text { FEA }\end{array}$ & $\begin{array}{c}B_{\mathrm{Z}}(\mathrm{T}) \\
\text { Analytical }\end{array}$ & $\begin{array}{c}F_{\mathrm{Z}}(\mathrm{N}) \\
\text { FEA }\end{array}$ & $\begin{array}{c}F_{\mathrm{Z}}(\mathrm{N}) \\
\text { Analytical }\end{array}$ \\
\hline 5 & 0,7118 & 0,7947 & 7081,4 & 8826 \\
\hline 10 & 0,5745 & 0,5893 & 4613 & 4853 \\
\hline 15 & 0,4628 & 0,4682 & 2993 & 3064 \\
\hline 20 & 0,3828 & 0,3884 & 2048 & 2109 \\
\hline 25 & 0,3241 & 0,3319 & 1467,6 & 1539,4 \\
\hline 30 & 0,2774 & 0,2897 & 1075,3 & 1173 \\
\hline 35 & 0,2402 & 0,257 & 806,5 & 923,4 \\
\hline 40 & 0,2084 & 0,231 & 607 & 746 \\
\hline 45 & 0,1824 & 0,2097 & 465 & 615 \\
\hline 50 & 0,1591 & 0,1921 & 353,6 & 515,6 \\
\hline 55 & 0,1397 & 0,1771 & 272,7 & 483,5 \\
\hline 60 & 0,1221 & 0,1644 & 208,5 & 377,6 \\
\hline 65 & 0,1074 & 0,1533 & 161,2 & 328,5 \\
\hline 70 & 0,0941 & 0,1437 & 123,82 & 288,4 \\
\hline
\end{tabular}

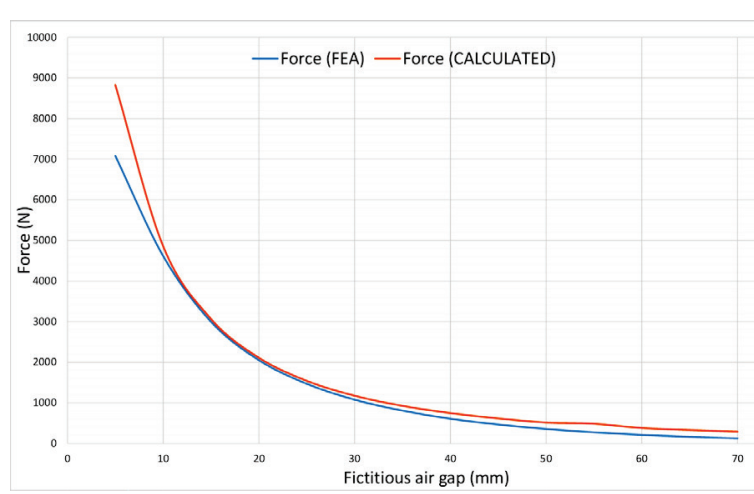

Figure 12 Analytically and FEA gained pull forces

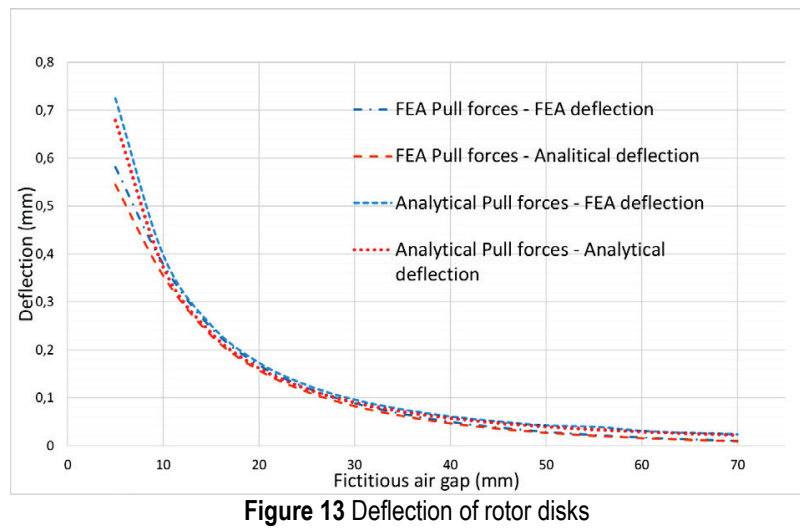

Deflection of rotor disks is calculated with Eq. (19) and determined with FEA, using SolidWorks software. In total, four deflections of rotor disks are calculated and presented in Tab. 4 and Tab. 5.
Fig. 13 shows the deflections of rotor disks for four scenarios. The first scenario is based on the FEA gained pull force, where force is calculated using Eq. (4) and FEA gained axial component of magnetic flux density $\left(B_{\mathrm{z}}\right)$ and simulated with FEA, using Solidworks software.

For second scenario, Eq. (19) is used for calculating deflection of rotor disks instead of FEA.

Table 4 Deflection of rotor disks for FEA gained pull forces

\begin{tabular}{|c|c|c|}
\hline $\begin{array}{c}\text { Fictitious air gap } \\
\text { thickness } d(\mathrm{~mm})\end{array}$ & $\begin{array}{c}\text { Deflection of rotor } \\
\text { disks (mm) } \\
\text { FEA }\end{array}$ & $\begin{array}{c}\text { Deflection of rotor disks } \\
(\mathrm{mm}) \\
\text { Analytical }\end{array}$ \\
\hline 5 & 0,5817 & 0,54475 \\
\hline 10 & 0,3788 & 0,35486 \\
\hline 15 & 0,2459 & 0,23023 \\
\hline 20 & 0,1684 & 0,15756 \\
\hline 25 & 0,1208 & 0,1129 \\
\hline 30 & 0,08874 & 0,082719 \\
\hline 35 & 0,06655 & 0,062044 \\
\hline 40 & 0,04987 & 0,046688 \\
\hline 45 & 0,03821 & 0,035761 \\
\hline 50 & 0,02909 & 0,027198 \\
\hline 55 & 0,02243 & 0,020975 \\
\hline 60 & 0,01725 & 0,016037 \\
\hline 65 & 0,01323 & 0,012398 \\
\hline 70 & 0,01019 & 0,0095249 \\
\hline
\end{tabular}

For third and fourth scenarios analytically calculated pull forces are used.

Table 5 Deflection of rotor disks for analytically gained pull forces

\begin{tabular}{|c|c|c|}
\hline $\begin{array}{c}\text { Fictitious air gap } \\
\text { thickness } d(\mathrm{~mm})\end{array}$ & $\begin{array}{c}\text { Deflection of rotor } \\
\text { disks (mm) } \\
\text { FEA }\end{array}$ & $\begin{array}{c}\text { Deflection of rotor disks } \\
(\mathrm{mm}) \\
\text { Analytical }\end{array}$ \\
\hline 5 & 0,7255 & 0,67898 \\
\hline 10 & 0,3985 & 0,37335 \\
\hline 15 & 0,2518 & 0,23567 \\
\hline 20 & 0,1734 & 0,16218 \\
\hline 25 & 0,1265 & 0,11843 \\
\hline 30 & 0,09613 & 0,090229 \\
\hline 35 & 0,07592 & 0,071009 \\
\hline 40 & 0,0613 & 0,057368 \\
\hline 45 & 0,05053 & 0,047276 \\
\hline 50 & 0,0424 & 0,039674 \\
\hline 55 & 0,03977 & 0,03372 \\
\hline 60 & 0,03106 & 0,029057 \\
\hline 65 & 0,02703 & 0,025266 \\
\hline 70 & 0,02383 & 0,0222 \\
\hline
\end{tabular}

Deflection of rotor disks is important for optimum thickness selection of rotor disk, which is selected based on the maximum allowed deflection $(y)$. When the geometry of rotor disks and PMs is defined (inner radius, outer radius, shaft and PM thickness) as well as maximum deflection, the thickness of fictitious air gap and corresponding axial component of magnetic flux density can be found in Tab. 2, Tab. 4 and Tab. 5. Once the corresponding axial component of magnetic flux density is obtained, Eq. (7), Eq. (14) and Eq. (19) can be rearranged to obtain the optimum disk thickness of rotor disks, where $q, M_{\mathrm{rb}}$ and $Q$ depend on the axial component of magnetic flux density.

$$
t=\sqrt[3]{\frac{\alpha_{\mathrm{1}} 12\left(1-v^{2}\right)\left(M_{\mathrm{rb}} a_{\mathrm{r}}^{2} C_{2}+Q_{\mathrm{b}} a_{\mathrm{r}}^{3} C_{3}+q a_{\mathrm{r}}^{4} L_{11}\right)}{E y}}
$$


Deflection of rotor disks (among other factors) depends on the stiffness factor (Eq. (14)), and the latter depends on the selected material and its thickness. Eq. (20) shows the derived thickness of rotor disks from Eq. (7), Eq. (14) and Eq. (19) for the purpose of direct calculation of rotor disk thickness.

\subsection{Validation of the Methodology}

Electromotive force (EMF) of the prototype described in Tab. 1 was measured at $600 \mathrm{rpm}$, using the Yokogawa WT1800 Power Quality Analyser.

The results are shown in Tab. 6 and the measuring equipment in Fig. 14.

Table 6 Measured RMS Values of the Back EMF

\begin{tabular}{|c|c|c|c|}
\hline $\mathrm{E}_{1}$ & $\mathrm{E}_{2}$ & $E_{3}$ & $\mathrm{E}_{\mathrm{avg}}$ \\
\hline 33,63 & 33,7 & 34 & 33,777 \\
\hline
\end{tabular}

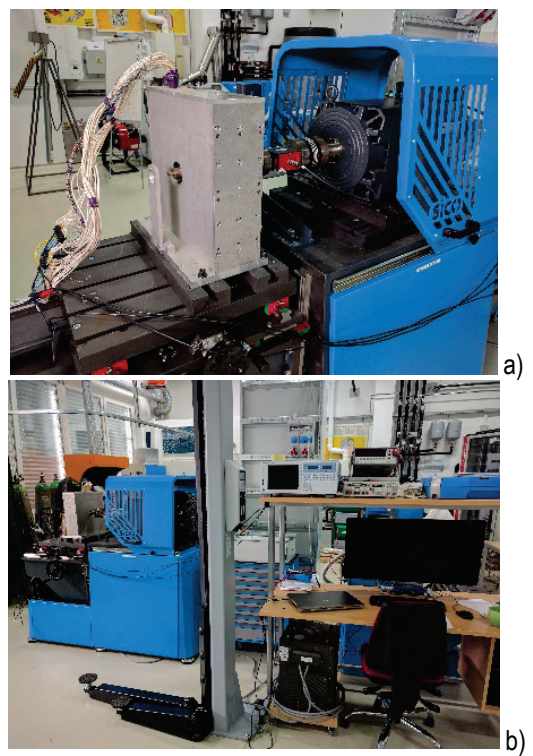

Figure 14 Measuring equipment: (a) Prototype AFPMM mounted on the measuring table, (b) complete view of measuring equipment

Analytical results are obtained by inputting the FEA gained axial component of magnetic flux density and the data from Tab. 1 into Eq. (21) and Eq. (22) [1].

$$
\begin{aligned}
& \Phi=\alpha_{\mathrm{i}} B_{\mathrm{d}} \frac{\pi}{8 p}\left(D_{\text {out }}^{2}-D_{\text {in }}^{2}\right) \\
& E=\pi \sqrt{2} f N k_{\mathrm{w}} \Phi
\end{aligned}
$$

Magnetic flux $(\Phi)$ can be calculated with Eq. (21) and RMS value of EMF with Eq. (22), where $\alpha_{\mathrm{i}}$ is the angle of PMs multiplied by the number of PMs per rotor disk (poles) and divided by 360 degrees ( $\alpha_{\mathrm{i}}$ also represents the magnet pitch to pole pitch factor), $B_{\mathrm{d}}$ the axial component of magnetic flux density, and $D_{\text {out }}$ and $D_{\text {in }}$ are the outer and inner diameters of PMs, respectively. $f$ is the network frequency $(50 \mathrm{~Hz}), N$ the number of turns in a coil, $k_{\mathrm{w}}$ the winding factor, $h$ the number of rotor disks and $I$ the rated current.

The calculations are performed for $B_{\mathrm{d}}$ in the middle of $17 \mathrm{~mm}$ fictitious air gap (as the prototype machine is constructed; $15 \mathrm{~mm}$ stator $+2 \times 1 \mathrm{~mm}$ air gap) and the results are shown in Tab. 7.
Table 7 Verification of the methodology calculated results

\begin{tabular}{|c|c|c|}
\hline $\begin{array}{c}\text { Magnetic flux } \Phi \\
(\mathrm{Wb})\end{array}$ & $B_{\mathrm{d}}(\mathrm{T})$ & $\begin{array}{c}\text { RMS value of Back } \\
\text { EMF }(\mathrm{V})\end{array}$ \\
\hline 0,001513 & 0,430753 & 32,46766 \\
\hline
\end{tabular}

Comparison of the average RMS value of measured EMF and the calculated value shows that the difference between them is less than $4 \%$.

\section{CONCLUSION}

Derivation of Eq. (18) shows the link between the axial component of magnetic flux density and the thickness of fictitious air gap. The value changes exponentially with the fictitious air gap thickness as shown in Fig. 11.

Since deflection of rotor disks (due to magnetic pull forces between opposite disks) is directly connected to the axial component of magnetic flux density, the deflection of rotor disks also changes exponentially. By changing a wellknown set of equations for circular plate deflection, a new equation for deflection of rotor disks is formed. Fig. 13 shows that the equations for deflection of rotor disks and axial component of magnetic flux density are quite accurate for initial dimensioning of rotor disk thickness.

The article presents a new and simple methodology for finding an optimum range of fictitious air gap thicknesses based on axial component of magnetic flux density of the PMs.

Since axial component of magnetic flux density is directly linked to magnetic pull forces, a modified equation for rotor disks deflection was derived and presented. Fig. 13 validates that equation is suitable for initial dimensioning of rotor disks, and compared to FEA analysis the accuracy is above $90 \%$, depending on the thickness of the fictitious air gap.

The methodology is also verified through measurement of the effective EMF value of the prototype machine. The results show that the methodology described in this article is accurate since calculated and measured RMS value of EMF differentiates less than $4 \%$.

\section{REFERENCES}

[1] Gieras, J. F., Wang, R. J., \& Kamper M. J. (2004). Axial Flux Permanent Magnet Brushless Machines. Dordrecht: Kluwer Academic Publishers.

[2] Chan, T. F. \& Lai, L. L. (2007). An Axial-Flux PermanentMagnet Synchronous Generator for a Direct-Coupled WindTurbine System. IEEE Trans. Energy Convers., 22(1), 8694. https://doi.org/10.1109/TEC.2006.889546

[3] Virtic, P., Pisek, P., Marcic, T., Hadziselimovic, M., \& Stumberger, B. (2008). Analytical Analysis of Magnetic Field and Back Electromotive Force Calculation of an AxialFlux Permanent Magnet Synchronous Generator with Coreless Stator. IEEE Transactions on Magnetics, 44(11), 4333-4336. https://doi.org/10.1109/TMAG.2008.2001528

[4] Wang, X. \& Xiao, K. (2009). Analysis for Magnetic Field in the Air Gap of the Wheel Multi-disc Coreless Permanent Magnet Synchronous Motor. Int. Conf. Electrical Machines and Systems, 1-4. https://doi.org/10.1109/ICEMS.2009.5382983

[5] Pinilla, M. \& Martinez, S. (2011). Selection of main design variables for low-speed permanent magnet machines devoted to renewable energy conversion. IEEE Trans. Energy Convers., 26(3), 940-945. https://doi.org/10.1109/TEC.2011.2157161 
[6] Kumar, S., Lipo, T. A., \& Kwon, B. (2016). A 32,000 $\mathrm{rev} / \mathrm{min}$ axial flux permanent magnet machine for energy storage with mechanical stress analysis. IEEE Trans. Magn., 52(7), 1-4. https://doi.org/10.1109/TMAG.2015.2512939

[7] Hatami, H., Bagher, M., Sharifian, B., \& Sabahi, M. (2013). A New Design Method for Low-Speed Torus Type AFPM Machine for Hev Applications. IJRET International Journal of Research in Engineering and Technology, 2(12), 396-406. Retrieved from http://esatjournals.net/ijret/2013v02/i12/ IJRET20130212067.pdf

[8] Pyrhonen, J., Jokinen T., \& Hrabovcova V. (2009). Design of Rotating Electrical Machines. Wiley and Sons, Wiley online.

[9] Fei, W., Luk, P. C. K., \& El-Hasan, T. S. (2011). Rotor integrity design for a high-speed modular air-cored axialflux permanent-magnet generator. IEEE Trans. Ind. Electron., 58(9), 3848-3858. https://doi.org/10.1109/TIE.2011.2106097

[10] Rani, J. A., Sulaiman, E., Omar, M. F., Ahmad, M. Z., \& Khan, F. (2015). Computational Method of Rotor Stress Analysis for Various Flux Switching Machine Using JMAG.IEEE Student Conference on Research and Development (SCOReD), 721-726. https://doi.org/10.1109/SCORED.2015.7449433

[11] Mueller, M. A., McDonald, A. S., \& Macpherson, D. E. (2005). Structural analysis of low-speed axial-flux permanent-magnet machines. IEE Proceedings-Electric Power Appl., 152(6), 1417-1426. https://doi.org/10.1049/ip-epa:20050227

[12] Timoshenko, S. (1987), Theory of Plates and Shells. New York, NY: McGraw-Hill Book Company.

[13] Young, W. C. \& Budynas, R. G. (2002). Roark's Formulas for Stress and Strain. New York, NY: McGraw-Hill Book Company.

[14] Virtic, P., Vražic, M., \& Papa, G. (2016). Design of an Axial Flux Permanent Magnet Synchronous Machine Using Analytical Method and Evolutionary Optimization. IEEE Trans. Energy Convers., 31(1), 150-158. https://doi.org/10.1109/TEC.2015.2477319

[15] Virtic, P. (2012). Analysis of rotor disk thickness in coreless stator axial flux permanent magnet synchronous machine. Przegląd Elektrotechniczny, 33(12), 12-15. Retrieved from http://pe.org.pl/articles/2012/12b/4.pdf

[16] Mbidi, D. N. (2001). Design and Evaluation of a $300 \mathrm{~kW}$ Double Stage Axial-Flux Permanent Magnet Generator. Thesis (MScEng)-Stellenbosch University. Retrieved from http://hdl.handle.net/10019.1/52177

\section{Contact information:}

Franjo PRANJIĆ, Master of Energy Technology

University of Maribor, Faculty of Energy Technology,

Hočevarjev $\operatorname{trg} 1,8270$ Krško, Slovenia

franjo.pranjic@um.si

\section{dr. Peter VIRTIČ}

University of Maribor, Faculty of Energy Technology,

Hočevarjev $\operatorname{trg} 1,8270$ Krško, Slovenia

peter.virtic@um.si 